\title{
Historical-epistemological elements for the design of a learning situation from Socioepistemology. The case of steady-state and electrical engineering
}

\section{Elementos históricos-epistemológicos para el diseño de una situación de aprendizaje desde la Socioepistemología. El caso del estado estacionario y la ingeniería eléctrica}

\author{
HINOJOS-RAMOS, Jesús Eduardo†* \& FARFÁN-MÁRQUEZ, Rosa María \\ Centro de Investigación y de Estudios Avanzados del Instituto Politécnico Nacional \\ ID $1^{\text {st }}$ Author: Jesús Eduardo Hinojos-Ramos / ORC ID: 0000-0003-3276-0322, CVU CONACYT ID: 598400 \\ ID $1^{\text {st }}$ Coauthor: Rosa María, Farfán-Márquez / ORC ID: 0000-0003-1229-8521, CVU CONACYT ID: 5811
}

DOI: $10.35429 / J T E R .2019 .15 .5 .20 .31$

Received January 02, 2019; Accepted March 12, 2019

\begin{abstract}
In this article, we present the results of a research in Socioepistemology (a theoretical framework in Mathematics Education), in which by the theoricalmethodological tool of the problematization of mathematical wits identifying elements for the social construction of mathematical knowledge related to steadystate in the works of 19th century scientists (Ohm, Thomson and Maxwell), these elements help in broadening the school promoted notions related to the mathematical wit of steady-state, considering the problems, paradigms and analogies created by the scientists as the situational context, and the steady-state as a signification context for the trigonometric Fourier series. These elements are used for the design of a learning situation in electrical engineering to study the steady-state in the static and dynamic scientific paradigms by working with analogies between steady-state heat propagation and diverse electrical phenomena. With the conclusion that these elements can be used to broaden the notion of steadystate from static to dynamic.
\end{abstract}

Mathematics Education, Steady-state, History, Epistemology

\begin{abstract}
Resumen
En el presente artículo, se presentan los resultados de una investigación en Socioepistemología (un marco teórico de la Matemática Educativa), donde a través de la herramienta teórico-metodológica de la problematización del saber matemático se identifican elementos para la construcción de conocimiento matemático relativo al estado estacionario en obras de científicos del siglo XIX (Ohm, Thomson y Maxwell), que permiten ampliar las nociones de este saber promovidas por la escuela, considerando los problemas, paradigmas y analogías creadas por los científicos como el contexto situacional, así como al propio estado estacionario como el contexto de significación para la serie trigonométrica de Fourier. Estos elementos son utilizados como insumo para el diseño de una situación de aprendizaje en ingeniería eléctrica donde se estudia el estado estacionario en paradigmas científicos estático y dinámico mediante el trabajo con analogías entre la propagación del calor en estado estacionario y fenómenos eléctricos diversos. Se concluye que estos elementos permiten ampliar la noción de estado estacionario de algo estático hacia algo dinámico.
\end{abstract}

Matemática Educativa, Estado Estacionario, Historia, Epistemologí

Citation: HINOJOS-RAMOS, Jesús Eduardo \& FARFÁN-MÁRQUEZ, Rosa María. Historical-epistemological elements for the design of a learning situation from Socioepistemology. The case of steady-state and electrical engineering. Journal of Teaching and Educational Research. 2019 5-15: 1-12

\footnotetext{
* Correspondence to Author (Email: jesus.hinojos@ cinvestav.mx)

$\dagger$ Researcher contributing as first author.
} 


\section{Introduction}

This research arises from teaching experience by questioning why we use the trigonometric Fourier series (TFS) in electrical engineering ?, Hinojos and Farfán (2017a) identify that TFS is seen in electrical engineering schools as a useful knowledge to solve certain types of problems: (1) decompose complicated periodic signals into a sum of simpler trigonometric functions (sine and cosine), (2) as a way of representing a periodic signal (by an algebraic expression) and (3) as a technique (in conjunction with the principle of superposition) to find values of voltages and currents in circuits fed with periodic non-sinusoidal sources. These meanings promoted in engineering schools allude to the fact that the TFS is a tool used to solve problems that are addressed in professional matters in electrical engineering programs. The curricular organization of the Department of Electrical Engineering offered by a Mexican university is considered as a particular case (figure 1), which is composed of three blocks and from which it is identified that the TFS appears for the first time in Signals and Systems, then in Electrical Circuits II and in Electronic Power Systems.

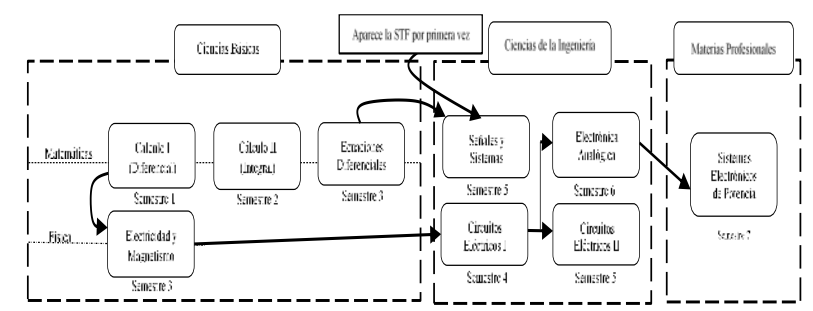

Figure 1 Curriculum tour in Electrical Engineering Source: Own Elaboration

The curricular organization shown corresponds to the orthodox model for engineering education (Herrera, 1990) that presents the curricula divided into three large blocks (Basic Sciences, Engineering Sciences and Professional Subjects), where professional subjects require the students to apply the knowledge acquired in the previous blocks. Despite the articulation of the mathematics that occurs in the Basic Sciences when the student reaches the subjects where he solves problems with the TFS, he presents some difficulties "the students have difficulties to use the mathematical tool in the professional subjects, referring in part to not remembering the formulas or not conceptualizing when the use of a certain calculation algorithm is valid " $(\mathrm{J}$. Beristáin-Jiménez, personal communication, April 29, 2016).
From a theory of Mathematics Education, Socioepistemology, it is attributed that these difficulties of the TFS presented by students are associated with the limitation of meanings promoted by the School Mathematical discourse ( $\mathrm{SMd}$ ), which is a social consensus validated by the school, that not only organizes the contents, but extends to establish the bases of communication and construction of meanings (Cantoral, Farfán, Lezama and Martínez-Sierra, 2006).

In addition, the SMd focuses its attention on the concepts of mathematical objects and their hierarchical organization, which for practical purposes in the classroom become algorithms; This way of presenting the mathematical objects has caused that the development of the mathematical activity is limited only to memorize and reproduce the language and rules of the algorithms to solve the problems (Cantoral, Montiel and ReyesGasperini, 2015).

A study in Socioepistemology (Farfán, 2012) identified that the TFS arose from the studies carried out by J.B. Fourier about heat in 1822 and where two contexts that give meaning to this mathematical knowledge are distinguished: (1) the propagation of heat as the situational context for performing mathematical activity, and (2) the steady state of temperatures such as context of significance from which the TFS and the study of its convergence emerged, however, the notion of steady state is not discussed in the school, but is given a priori when analysing electrical circuit problems. Hence the question why is the trigonometric Fourier series used in electrical engineering? It is reformulated considering these two contexts to: 1) What is the relationship between the propagation of heat and electricity, in steady state? and 2) what are the sub-elements for social construction that make up the steady state in the electrical phenomenon?

Given the importance of the steady state for the TFS, this article presents the design of a learning situation based on socio-epistemology with which it is intended to expand the school promoted meanings of the notion of steady state in the disciplinary framework of engineering electric; and from this investigation its results are expected to give elements for the redesign of the TFS's SMd. 


\section{Theoretical framework}

Mathematics Education is a scientific discipline that studies the didactic phenomena related to mathematics as a body of knowledge that is used by different human groups to solve tasks or problems that arise in their daily life, professional activity or in scientific work such as technological development or the same mathematics (Cantoral and Farfán, 2003). The research community within this discipline has also addressed the social elements that permeate mathematical activity (Lerman, 2000).

Socioepistemology is a theoretical framework that seeks the democratization of learning through the social construction of mathematical knowledge and its significance, taking into account the practices that accompany the use of mathematics instead of focusing solely on the mathematical object. The social approach of Socioepistemology includes situational and interactional aspects, but primarily the value of the use of mathematics for the problem it solves (Cantoral, 2013).

Therefore, this theory considers that mathematical knowledge does not have preexisting meanings to experience, but rather arises from human activity and expands as mathematical knowledge is used to solve problems.

Thus, the way in which Socioepistemology studies the social construction of mathematical knowledge is through problematization, with which it questions the status of mathematics and identifies how it is constructed and transmitted in particular scenarios, to later design learning situations for classroom intervention; that is, it is not intended to generate a fictional genesis of the emergence of mathematics in a given scenario, but to enhance the elements that allow the social construction of meanings (Cantoral and Farfán, 2003).

\section{Methodological considerations}

The problematization is a theoreticalmethodological tool that consists in studying the use of mathematical knowledge through four dimensions: didactic, cognitive and epistemological, permeated by the social dimension (Cantoral, 2013).
In problematization, the uses of mathematical knowledge are identified as part of a culture, a product of human activity context of significance. The situational context refers to the conditions where knowledge is given, which are framed at a specific time and place, while the context of significance indicates the way in which mathematical knowledge is constituted and the value it has to solve problems (Cantoral, Montiel and Reyes-Gasperini, 2015).

To study the epistemological dimension through problematization, a historicalepistemological analysis (historization) is carried out in original scientific works that, in addition to considering historical facts, identifies the emergence of a specific mathematical knowledge, the social and cultural circumstances of the Age of the authors, the elements that allowed the build and configuration of the work and the problem that was solved or tried to be solved.

This study allows us to question the value of the use of mathematics in the context of the emergence of knowledge itself and identify elements for its social construction, through the author's mathematical activity and its reconstruction.

The historization then provides design principles for the elaboration of learning situations that are applied to a group of students, and of which their mathematical activity is contrasted with that of the author of the scientific work; and this contrast seeks to identify the invariant elements in mathematical activity for the construction of mathematical knowledge meanings.

Specifically in the historicization are identified: (1) an author and his work located in the historical moment in which it was written, (2) the author's intention to create his work and the problem to which he gave or tried to solve, (3) the mathematical tools or techniques used / created to develop his work, (4) the paradigm of scientific thought, (5) the mathematical work done which is reconstructed using the current tools, (6) the main mathematical result of the work and its relationship with current knowledge, and (7) the elements of social construction of mathematical knowledge of the work (the invariants among the works) to establish an epistemological hypothesis that supports the design of learning situations. 
The learning situation presented in this article is based on the historicization made by Hinojos and Farfán (2017b) of the work of three scientists of the nineteenth century (G. S. Ohm, W. Thomson and J. C. Maxwell); In the following sections it is detailed: what elements of the historization allowed to configure a hypothesis to elaborate the learning situation, the organization and content of the tasks, and what is expected to be obtained as production when carrying out a didactic intervention.

\section{Results}

Based on Farfán's research (2012), where Fourier's work identifies the propagation of heat as the situational context and the steady state as the context of significance for the emergence of the TFS. Fourier's work greatly inspired the nineteenth-century scientific community (Narasimhan, 1999), in the case of theories about electricity, it was the basis for the mathematization of electrical conduction $(\mathrm{Ohm})$, the theorizing about electrostatic equilibrium (Thomson) and the transmission of messages by telegraph over long distances (Maxwell), Figure 2 illustrates the historical review map.

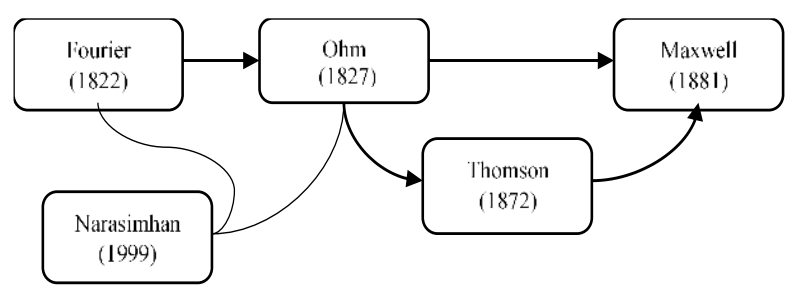

Figure 2 Historical review map

Source: Built from (Hinojos and Farfán, 2017b)

Next, as mentioned in the methodological considerations section, the historical scheme for the works of Ohm, Thomson and Maxwell is shown, with the exception of the last step, which is identified with a cross-sectional analysis of the works (section 3.4 ).

\section{Results in Ohm}

Author and work. G. S. Ohm, was a German scientist who was born in the late eighteenth century, known primarily for his contributions to theories about galvanism (currently electric current), in particular his work Die Galvanische kette Mathematisch Bearbeitet (written in 1827) was analyzed.
Intention of the work. Ohm's intention was to provide theories of galvanism with mathematical rigor that until now had only been studied qualitatively, this was done through laboratory experiments with circuits formed by conductive wires and voltaic batteries, and using analogies with other physical phenomena, mainly with the spread of Fourier heat.

Tools or mathematical techniques. The mathematical work carried out by Ohm consisted of establishing the equivalence between galvanism and the propagation of heat, so that the electrical conduction could be modeled on solid wires based on the Fourier work of 1822, we call this the establishment of a semiformal analogy insofar as it mathematizes the phenomenon working in tandem with the physical considerations that model it. Mathematically, the author used the Taylor series and notions of differential calculus to find a differential equation that models the change of voltage over time in a galvanic circuit.

Paradigm of scientific thought. In a dynamic paradigm, the electric current is called galvanic fluid and is considered a substance that moves through the bodies and fills them in full.

Reconstruction of mathematical work. $\mathrm{Ohm}$ begins by defining the parameters involved in the galvanic phenomenon: a conductive wire can be considered as a set of disks of infinitely small thickness with constant radius, as the length of the conductor is much larger than the width and height, the conduction is only performed in one direction (declared with respect to the $\mathrm{x}$ axis), this way of considering the wire is illustrated in Figure 3.

In relation to Fourier's work, this is equivalent to his physical model for the propagation of heat along a bar of infinite length.

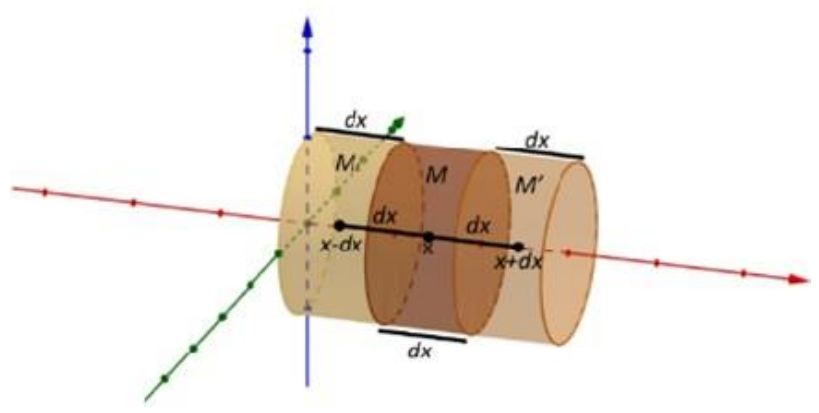

Figure 3 Ohm's conductor wire model Source: (Hinojos and Farfán, 2017b, p. 76) 
Declares that the amount of electricity transferred $(\rho)$ in the entire wire is proportional to the conduction quality (conductivity constant, $\chi$ ) and the constant difference of the electroscopic forces (voltages, $\mathrm{u}^{\prime}-\mathrm{u}$ ) in a infinitely small time interval $(\partial t)$ and inversely proportional to the distance that separates the centers of each disk (s).

$\rho=\frac{\chi\left(u^{\prime}-u\right) \partial t}{s}$

This expression is used to determine the amount of electricity that passes from one disk to another in the model in Figure 3. If we select any of the disks, and imagine another one whose distance from the first is $\mathrm{x}$, then $\mathrm{dx}$ represents the thickness of the disk that will be designated $\mathrm{M}$. The electroscopic force (voltage) will be $\mathrm{u}$ at time $t$, for the disk $M$ located at $x$. From this it follows that $\mathrm{u}$ is a function that depends on the distance $\mathrm{x}$ and the time $\mathrm{t}$; what in current notation would be $u(x, t)$.

If the electroscopic force on the disks immediately before ( $\left.\mathbf{M}^{\prime}\right)$ and after $\left(\mathrm{M}_{1}\right)$ at $\mathrm{M}$ is $\mathrm{u}^{\prime}$ and $\mathrm{u}_{1}$ for the positions of $\mathrm{x}+\mathrm{dx}$ and $\mathrm{x}-\mathrm{dx}$ respectively, the distance from the center of the disks $M^{\prime}$ and $M_{1}$ to the center of disk $M$ will correspond to the distance $\mathrm{dx}$.

Consequently, the expression $\rho=$ $\frac{\chi\left(u^{\prime}-u\right) \partial t}{s}$ will change to be considered $\rho^{\prime}=$ $\frac{\chi\left(u^{\prime}-u\right) \partial t}{\partial x}$ on the disk $M^{\prime}$ and $\rho_{1}=\frac{\chi\left(u_{1}-u\right) \partial t}{\partial x}$ on the disk $M_{1}$. The total change in the amount of electricity for the disk $M$ during the time interval $\mathrm{dt}$, will be in this case the sum of the expressions $\rho^{\prime}$ and $\rho_{1}$.

$\rho=\frac{\chi\left(u_{1}-u\right) \partial t}{\partial x}+\frac{\chi\left(u^{\prime}-u\right) \partial t}{\partial x}$

Algebraically the expression is reduced to:

$\rho=\frac{\chi\left(u_{1}+u^{\prime}-2 u\right) \partial t}{\partial x}$

As $u=u(x, t), u^{\prime}=u(x+\partial x, \partial t)$ and $u_{1}=u(x-\partial x, \partial t)$.

Both expressions ( $\mathrm{u}^{\prime}$ and $\mathrm{u}_{1}$ ) are developed using the Taylor series for a variable with respect to $\mathrm{x}$, the expression of $\rho$ is reduced to: $\rho=\chi \frac{\partial^{2} u}{\partial x^{2}} \partial x \partial t$

Considering the absolute conductivity $\chi=\omega \chi$ (where $\omega$ is the magnitude of disk mass) and the effects of the atmosphere on the conducting body bcu $\partial \mathrm{x} \partial \mathrm{t}$, this is in accordance with Coulomb's theory about the effect of the atmosphere on the conducting bodies, where $b$ is the atmospheric coefficient, $c$ the circumference of the disk and $u$ the voltage. The expression for $\rho$ is extended to:

$\rho=\chi \omega \frac{\partial^{2} u}{\partial x^{2}} \partial x \partial t-b c u \partial x \partial t$

So, Ohm considers the total change of the electroscopic force for the M disk as:

$\Delta_{T_{0} t_{u}}=\gamma \omega \frac{\partial u}{\partial t} \partial x \partial t$

Where $\gamma$ is a hypothetical parameter proposed by $\mathrm{Ohm}$, to emulate the heat capacity of bodies proposed in Fourier heat theory.

To maintain the energy balance in the circuit, both expressions ( $\rho$ and $\Delta_{\text {Tot }_{u}}$ ) they must be the same:

$\chi \omega \frac{\partial^{2} u}{\partial x^{2}} \partial x \partial t-b c u \partial x \partial t=\gamma \omega \frac{\partial u}{\partial t} \partial x \partial t$

That when simplifying algebraically results in the expression, which is a partial differential equation of the second order whose solution allows to find the value of the voltage anywhere in the circuit:

$\gamma \frac{\partial u}{\partial t}=\chi \frac{\partial^{2} u}{\partial x^{2}}-\frac{b c}{\omega} u$

Main mathematical result. Ohm uses the differential equation he obtains to propose three solutions.

Solution 1. When the circuit is independent of time and the atmosphere does not influence it. These considerations result in a linear function for the voltage that depends on the distance where the measurement is made. $\mathrm{u}(\mathrm{x})=\frac{\mathrm{a}}{\mathrm{l}}(\mathrm{x}-\lambda)+\alpha$, where $\mathrm{a}$ is the value of the source, 1 the length of the circuit, $\lambda$ the place where the measurement was made and $\alpha$ some voltage provided by external factors. 
Solution 2. When the circuit is independent of time and the atmosphere influences it. These considerations cause the left side of the differential equation to be zero, $\frac{\partial^{2} \mathrm{u}}{\partial \mathrm{x}^{2}}-$ $\frac{b c}{\chi \omega} u=0 \quad$ (rearranged and simplified), this equation is solved by $\mathrm{Ohm}$ by means of undetermined coefficients, obtaining $\mathrm{u}(\mathrm{x})=$ $\frac{1}{2} \mathrm{a}\left(\frac{\mathrm{e}^{\beta \mathrm{x}}-\mathrm{e}^{-\beta \mathrm{x}}}{\mathrm{e}^{\beta(1)}-\mathrm{e}^{-\beta(1)}}\right)$, where $\beta^{2}=\frac{\mathrm{bc}}{\chi \omega}, \mathrm{a}$ is the source voltage and circuit length.

Solution 3. When the circuit is not independent of time and the atmosphere influences. Under these considerations, Ohm divides the solution into what happens while time affects the (transitory) phenomenon and what happens when the phenomenon is independent of time (steady state). The solution consists of the sum of both states, obtaining the expression $\quad \mathrm{u}=\frac{\mathrm{a}}{2 \mathrm{l}} \mathrm{x}+$ $\mathrm{a}\left[\sum_{\mathrm{i}=1}^{\infty}\left(\frac{\mathrm{i} \pi}{\mathrm{i}^{2} \pi^{2}+\mathrm{l}^{2}}\right) \operatorname{sen}\left(\frac{\mathrm{i} \pi(\mathrm{x}+\mathrm{l})}{\mathrm{l}}\right) \mathrm{e}^{-\frac{\mathrm{xi}^{2} \pi^{2} \mathrm{t}}{1^{2}}}\right], \quad$ where the term that contains the summation consists of sine functions with a negative exponential coefficient that depends on time, this term decreases as time tends to infinity until it disappears, which corresponds to the steady state.

\section{Results in Thomson}

Author and work. W. Thomson (Lord Kelvin) was a British scientist who was born in the 19th century, who carried out various works on thermodynamics and electricity. The work that was analyzed is part of a compendium of scientific articles by the author about his research in electrostatics and magnetism (from 1872), particularly his articles On the Motion of Heat in Homogeneous Solid Bodies, and its Connexion with the Mathematical Theory of Electricity and On the Mathematical Theory of Electricity in Equilibrium.

Intention of the work. Thomson's work on electricity was oriented to the search for mathematical analogies between thermal and electrical phenomena (Acevedo, 2004); The way to analyze the distribution of electricity, the physical model of propagation of one particle to another through a medium, the distance action and the geometric representation of the flow of electricity were some of the mathematical analogies proposed by Thomson through the comparison of the phenomena.
Tools or mathematical techniques. In particular, Thomson used material analogies between physical models, notions of steady state and isothermal surfaces to explain electrostatic problems.

Paradigm of scientific thought. In a static paradigm, based on Coulomb's theories about electrostatic interaction (which takes Newton's model of distance action to model the force of attraction), the electric charge does not contemplate the influence of the electric field with the surrounding environment and it is conceptualized as a substance that fills the bodies.

\section{Reconstruction of mathematical work.}

In Thomson's revised works, the author focuses on establishing direct physical equivalences between the phenomena of steady state heat propagation and electrostatic equilibrium. These equivalences are considered a material analogy, as they refer to direct correspondences between phenomena without reaching a mathematical model (as in the case of Ohm). Based on this theorization, Thomson concludes that Fourier theorems are applicable to the case of electrostatics.

Main mathematical result. Thomson's main result was the equivalence between the phenomena in the static paradigm, which consists of visualizing the propagation of heat in a steady state and a system of bodies charged by induction in electrostatic equilibrium, establishing the equivalence between the physical parameters of each one ( figure 4).

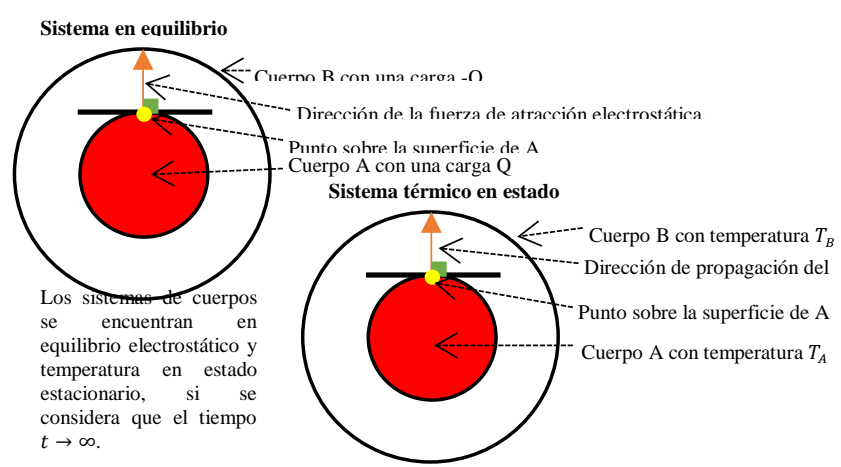

Figure 4 Thomson's analog model

\section{Results in Maxwell}

Author and work. J. C. Maxwell was a Scottish scientist who was born in the 19th century, whose most important contributions were in the field of electromagnetic theory and electromagnetism.

HINOJOS-RAMOS, Jesús Eduardo \& FARFÁN-MÁRQUEZ, Rosa María. Historical-epistemological elements for the design of a learning situation from Socioepistemology. The case of steady-state and electrical engineering. Journal of Teaching and Educational Research. 2019 
The work analyzed was volume 1 of the book A Treatise on Electricity and Magnetism (published in 1881 posthumously).

Intention of the work. The work was written with the intention of generating an official text for Physics at the University of Cambridge, this is indicated by Maxwell in the preface where other scientists added posthumous notes.

Tools or mathematical techniques. It establishes the equivalences between the propagation of heat and the conduction of messages from a telegraphic cable using vector notations and calculation of quaternions, the mathematical theory of Ohm's galvanism, the theory of heat propagation, notions of steady state and transient analysis for electrical circuits. From this study, this type of equivalence is recognized as a formal analogy as it establishes the physical similarity between phenomena and mathematizes it, but the mathematical model is independent of the physical.

Paradigm of scientific thought. Framed in a dynamic paradigm about the conduction of electricity, Maxwell solved the problem of the transmission of messages by telegraph by analyzing a circuit equivalent to the telegraph cable and an analogy between the propagation of heat and the transmission of messages, with which he obtained a model mathematician where he considered the transitory of sending the message and the steady state; We identify this as a formal analogy because in addition to establishing the physical similarity analogy of phenomena, it also achieves its mathematization..

\section{Reconstruction of mathematical work.} To construct the formal analogy with the propagation of heat, Maxwell considered that the ability of bodies to retain heat cannot be reproduced identically in an electrical phenomenon, however, something similar is observable in the transmission of messages through transatlantic telegraph (figure 5) and mathematically modeled with the Fourier heat propagation equation.

In the circuit shown, the resistance (R) and capacitance $(C)$ value is considered to be the same in each section, while the values for the electric charges in each capacitor $\left(Q_{n}\right)$ are different given the distribution of the input load $\left(Q_{0}\right)$.
The electric charge on each capacitor would be given by $Q_{n}-Q_{n+1}=C P_{k}$, where $P_{k}$ corresponds to the electrical potential of the node with respect to ground; in the case of the first node, its voltage would be given by $P_{1}=$ $\frac{Q_{0}-Q_{1}}{C}$, for the second it would be $P_{2}=\frac{Q_{1}-Q_{2}}{C}$, and so on for each node.

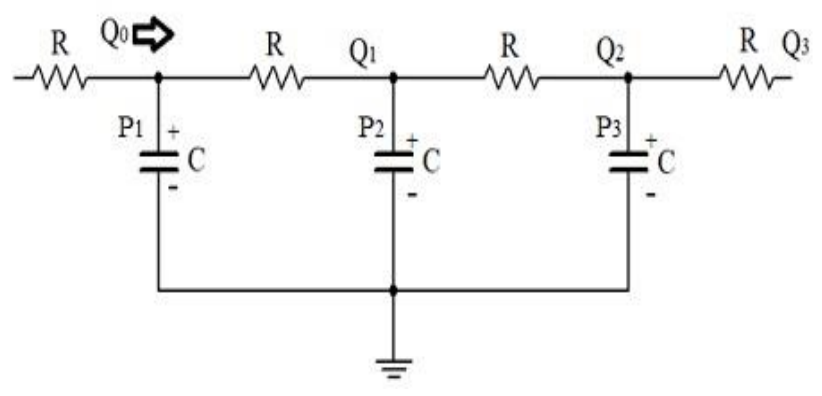

Figure 5 Maxwell's model of the transatlantic telegraph

Subsequently, through Ohm's law, you have that the potential difference is $P_{k}-P_{k+1}=$ $R I$; and as the current is the change of the load with respect to time $I=\frac{d Q}{d t}$; replacing in Ohm's law you get $P_{k}-P_{k+1}=R \frac{d Q_{n+1}}{d t}$.

Given this, for each resistance in the circuit the expressions would have $P_{1}-P_{2}=$ $R \frac{d Q_{1}}{d t} ; P_{2}-P_{3}=R \frac{d Q_{2}}{d t} ; P_{3}-P_{4}=R \frac{d Q_{3}}{d t}$; and so on.

Substituting the expressions of the potentials as a function of the electric charge we have a set of equations with the form $Q_{n}-$ $2 Q_{n+1}+Q_{n+2}=R C \frac{d Q_{n+1}}{d t}$.

If a general model is considered in which each section of the circuit has the same magnitude for the parameters of $\mathrm{R}$ and $\mathrm{C}$; for a voltage $\mathrm{V}$ the total amount of $\operatorname{load} \mathrm{Q}$ at the beginning of the circuit observed in each node between remote sections an infinitely small distance (from the section in $\mathrm{x}$ to the section $x+$ $\partial x)$ you get the expression $Q-\left(Q+\frac{d Q}{\partial x} \partial x\right)=$ $-\frac{d Q}{d x} \partial x$; which is equivalent to the expression of the charge in a capacitor $-\frac{\partial Q}{\partial x}=C v$ (the sign indicates the direction of the current).

For the voltage component along the axis $x\left(v_{x}=-\frac{\partial v}{\partial x}\right)$, by Ohm's law you have $v_{x}=R I$, and substituting the equivalences established above, you get $-\frac{\partial v}{\partial x}=R \frac{\partial Q}{\partial t}$.

HINOJOS-RAMOS, Jesús Eduardo \& FARFÁN-MÁRQUEZ, Rosa María. Historical-epistemological elements for the design of a learning situation from Socioepistemology. The case of steady-state and electrical engineering. Journal of Teaching and Educational Research. 2019 
Clearing $\partial \mathbf{Q}$ of both equations, equating them and simplifying algebraically you have the expression $\frac{\partial v}{\partial t}=\frac{1}{R C} \frac{\partial^{2} v}{\partial x^{2}}$. If the circuit is considered to be affected by the surrounding environment (given a non-perfect insulation), the model for insulation resistance, by the cylindrical geometry of the wire, is given by the expression $R_{\text {ais }}=\frac{1}{2 \pi} \rho \operatorname{Ln}\left|\frac{r_{1}}{r_{2}}\right|$, where $\rho$ is the specific resistance of the insulating material and $r_{1}, r_{2}$ they correspond to the inner and outer radii of the center of the wire towards the insulator and towards the surface in contact with the surrounding medium.

The loss towards the environment is given by the expression $v_{a m b}=\frac{1}{R_{a i s} C} v$. Combining the differential equation with the loss towards the environment there is a model for the voltage change:

$C \frac{\partial v}{\partial t}=\frac{1}{R} \frac{\partial^{2} v}{\partial x^{2}}-\frac{1}{R_{a i s}} v$

Main mathematical result. The model obtained by Maxwell is a partial differential equation of the second order that can be used to know the value of the voltage over time in any section of the cable. Maxwell unlike Ohm does not show solutions for the model, however, we can see that both models are mathematically equivalent: $\gamma \frac{\partial u}{\partial t}=\chi \frac{\partial^{2} u}{\partial x^{2}}-\frac{b c}{\omega} u$ y $C \frac{\partial v}{\partial t}=\frac{1}{R} \frac{\partial^{2} v}{\partial x^{2}}-$ $\frac{1}{R_{\text {ais }}} v$. When comparing both models, it is necessary that $\gamma$ and $\mathrm{C}$ correspond analogously to the heat capacity of the bodies. The transitory one is considered by Maxwell at the time of indicating that the sending of messages by telegraph takes a certain time in being realized, since in the equivalent circuit it takes some time to load each capacitor and the message is sent until all the capacitors are loaded; in relation to the steady state, this can be found by using the differential equation to model the transmission of messages when time is considered $t \rightarrow \infty$.

\section{Elements of social construction of the notion of steady state}

From the historization of Hinojos and Farfán (2017b), an epistemological hypothesis is configured for the construction of the notion of stationary state: mathematical knowledge related to the stationary state is constructed by transiting between the static and dynamic paradigms with the establishment of material analogies. semiformal-formal heat and electricity.
Therefore, for the design of the learning situation that we present, we start from the following elements of social construction: (1) recognize that before the steady state the transitory is given as a previous process; (2) establish the material-semiformal-formal analogies to recognize that the steady state requires both to identify the similarity between physical phenomena and their mathematization, where this mathematization is independent of the phenomenon; and (3) the transition from a static to a dynamic paradigm, to consider that the steady state has a constant behavior but that it can also have small bounded and periodic variations over time.

\section{Design of the learning situation}

\section{Organization of the tasks}

The learning situation is constructed as a sequence of four tasks that begins in a static paradigm by establishing a material analogy (identifying the equivalence between the physical rationality of phenomena); later in a dynamic paradigm a semiformal analogy is constructed (by means of the equivalences between the physical rationality and the mathematization of the stationary state); this analogy becomes formalized in a dynamic paradigm (through its mathematization); and finally it deepens the notions about the steady state in problems related to the analysis of electrical circuits. The complete learning situation can be consulted in the following link.

\section{Main content of the tasks}

\section{Homework 1}

Task 1 is based on Thomson's work, it seeks to establish the material analogy between the propagation of heat at steady state with a system of bodies in electrostatic equilibrium in a static paradigm. The material analogy consists in identifying the direct equivalences between the thermal and electrostatic parameters; this through the construction of thermal systems (two bodies at different temperatures, but constant, steady state) and electric (two bodies electrically charged by induction, in electrostatic equilibrium). It was chosen to start with Thomson's analogy, given that the paradigm is static and the notion of steady state is related to the notions of equilibrium, even though Ohm's work first arose. 
The task is divided into three parts: (1) theoretically establish a diagram representing the thermal system in steady state, (2) develop a diagram of a system of charged bodies in electrostatic equilibrium and (3) make the comparison between the physics of both diagrams to identify equivalences and thus raise the material analogy (figure 6).

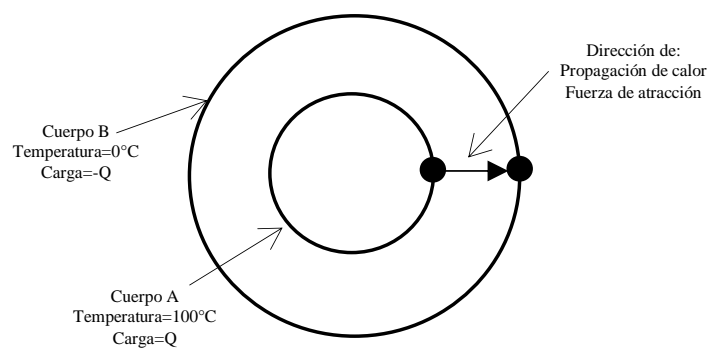

Figure 6 Thomson's analogy

\section{Task 2}

Task 2 is based on Ohm's work, it seeks to establish a semi-formal analogy between the propagation of heat and electrical conduction in a dynamic paradigm, this through the consideration of the transient and the steady state of both systems. The semi-formal analogy is made by identifying physical equivalences and mathematizing the electrical phenomenon.

The task is divided into two parts: (1) develop the physical problem of the propagation of heat in steady state and the conduction of electricity through a wire, in such a way that the direct analogy and the differences between both kinds of phenomena, considering the transitory and the steady state; and (2) based on a demonstrative reading of the mathematical development of the problem of conducting electricity on a wire, answer three reflection questions about the analogy, the development of the problem and its mathematization.

An extract of the designed task is shown in Figure 7, where the comparison is made between the way in which heat is propagated along a body and how the electric current is established.

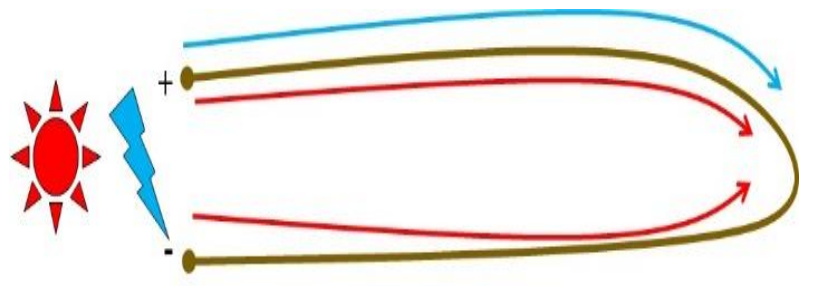

Figure 7 Excerpt from task 2

\section{Task 3}

Task 3 is based on Maxwell's work, it seeks to establish a formal analogy (mathematized) between the propagation of heat in steady state and the transmission of messages through the transatlantic telegraph in a dynamic paradigm; in both cases, both the transitory and the steady state of the phenomena are taken into consideration. The task is divided into four parts described below.

In the first part three different situations are contemplated: (1) a problem where an analogy is made between a system of bodies with steady state temperature and another system of bodies with electric charge by induction, and deepens the differences between the two, since the similarities were explored in task 1 ; (2) a problem of heating / cooling a thick plate and its analogy with some electrical phenomenon, so that students use their knowledge of physics to find the equivalent; and (3) a hypothetical situation of the transmission of a message by telegraph during the nineteenth century, to encourage reflection on the speed of transmission of the message; referring to the latter situation, figure 8 is shown.

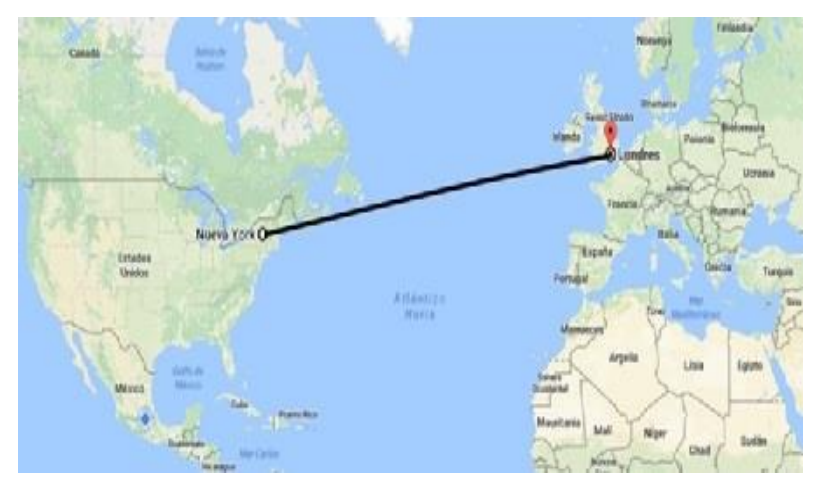

Figure 8 Telegraph problem

The second part of the task presents a problem where it is considered a resistance to heat water and reflects on the speed of the temperature increase and the establishment of the electric current.

The purpose of this part of the task is to show that, although the phenomenon of heat and electricity propagation is similar, the electric current produces an increase in temperature, but the behavior of both is not identical. 
The third part of the task consists of four subsections, where the approach of the problem that allowed Maxwell to obtain the equation for the transmission of messages by transatlantic telegraph is carried out, by analyzing a circuit equivalent to the telegraph from which a model is obtained based on basic laws of electricity (Ohm's law) and the concept of capacitance; at the end, the second differential partial differential equation obtained by Maxwell is shown.

The fourth part takes up the equation shown at the end of Task 2 (from Ohm), the Maxwell differential equation (shown in the third part) and the Fourier partial differential equation for heat propagation; through a table the parameters of the three differential equations are compared, three reflection questions are asked regarding the comparison between them and the way in which they can be analyzed to study the transient and the steady state of the phenomena.

\section{Task 4}

Task 4 is based on problems of analysis of electrical circuits and power electronics, with them it seeks to deepen the notions of the transient and the conditions in which the steady state in electrical circuits occurs in a dynamic paradigm, taking as base the knowledge built on tasks 1, 2 and 3 . The task is divided into three parts described below..

In the first part, a parallel resistivecapacitive (RC) arrangement is presented (figure 9), separated from the power supply by means of a switch that is initially closed; The circuit is analyzed considering the two states of the switch (open and closed) and subsequently switching the switch periodically and analyzing the behavior of the waveforms in the circuit resistance.

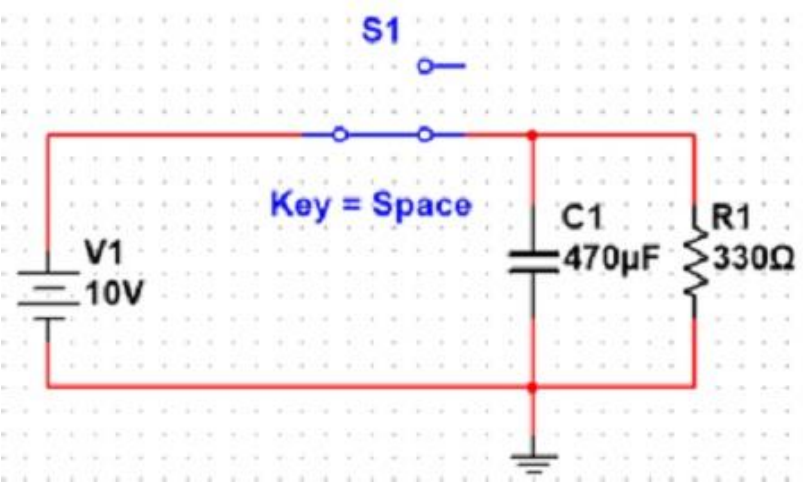

Figure 9 Circuit 1

Source: Own Elaboration

ISSN 2444-4952

ECORFAN® All rights reserved
The second part shows an RC circuit connected in series (figure 10) to a voltage source and an arrangement of switches. It is indicated that, when starting to analyze the circuit, the switches are closed and both change position simultaneously. From the circuit, the waveforms that are observed in the resistance are analyzed considering the switches closed, open and switching periodically.

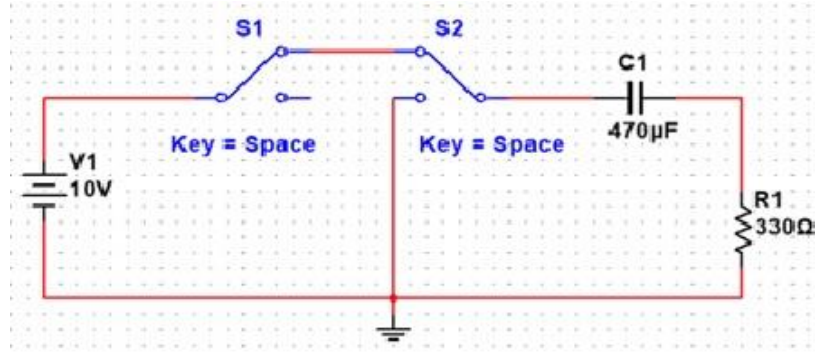

Figure 10 Circuit 2

Source: Own Elaboration

The third part consists of two direct current converter circuits (a reducer and a voltage booster). The circuits and voltage waveforms that are obtained on a large scale are presented (both the transient and the steady state are appreciated) and a small-scale approach (only the steady state is appreciated) (figure 11), for each question is asked about the characteristics of the waveforms, their transient and the steady state.
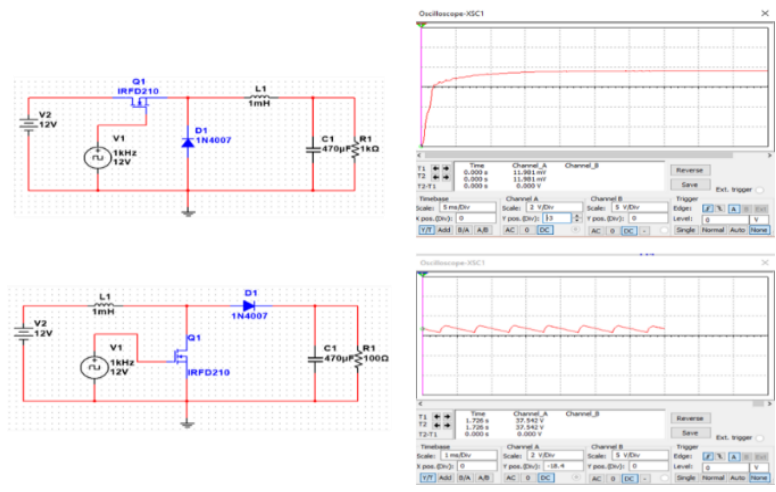

Figure 11 Converter circuits Source: Own Elaboration

\section{Conclusions}

As it was shown in section 3, by means of the historization we identify in the original works the epistemological elements that allude to the development of mathematical knowledge related to the steady state: the authors, their work and their social context, the intentions for the writing of their works, the mathematical tools or techniques used, the paradigm of the scientific thought of the time, the mathematical work, its reconstruction and its main results.

HINOJOS-RAMOS, Jesús Eduardo \& FARFÁN-MÁRQUEZ, Rosa María. Historical-epistemological elements for the design of a learning situation from Socioepistemology. The case of steady-state and electrical engineering. Journal of Teaching and Educational Research. 2019 
In particular, in the case of this investigation, the work of each author is determined (Ohm, Thomson and Maxwell): their paradigm (static or dynamic), the particular problem they solved (electrical conduction, electrostatic balance and transmission of telegraphic messages, respectively) and the type of analogy developed (material, semi-formal and formal). These elements configure the situational context for the mathematical work that is led to the design of the learning situation, and with a cross-sectional analysis of the works, we infer that the notion of steady state is the context of significance for said mathematical work, as reported Farfán (2012) in the case of heat, which is discussed in the designed learning situation.

The identification of both contexts (situational and of significance) provide the inputs for the elaboration of the learning situation; in the case of the situational context, the focus is not to generate a situation that simulates the scientist's work but to take the epistemological elements identified for the mathematical work, particularly the problem that was solved and the analogies between the phenomena; the context of significance, on the other hand, is necessary to generate it as the basis of design since it gives meaning to mathematics to broaden the notion of steady state from a static paradigm to a dynamic one.

The learning situation presented in section 4, was used in a group of electrical engineering students who studied the subject of Power Electronics in the August-December 2018 semester (belonging to the block of Professional Subjects). Currently the research project is in the in-depth analysis of these data, with which it has been identified that the idea of electricity as a substance tends to diminish as one works with formal analogies; idea that corresponds to an epistemological obstacle (Bachelard, 2000) related to the development of electrical sciences, which is giving characteristics of a substance by what can be perceived by the senses to phenomena that are not substances. The presence of this obstacle alludes to the complexity of phenomena that are in a steady state such as heat and electricity, whose confrontation is necessary for the construction of mathematical knowledge.

The idea of electricity as a substance was identified in the works of Ohm and Thomson.
Ohm considered electrical conduction as a substance that moves through bodies and fills them in full, while Thomson conceptualized electric charge as a substance that fills bodies. But when arriving at the work of Maxwell this idea is confronted thanks to the dimensions of the components of the transatlantic cable that allowed to identify that the electricity does not travel at the speed of the light, but that the cable is equivalent to an electrical circuit that requires a time to load, which was not noticeable given the laboratory components that Ohm had.

So far, in the data analysis it has been identified that the notion of steady state in a static paradigm is related to the tendency to a constant value. With the full analysis it is hoped to identify that this notion is extended by moving towards the dynamic paradigm; and also contrast the mathematical activity of students and scientists to validate and adjust as necessary the elements of social construction of the steady state that were proposed as the context of significance.

\section{References}

Acevedo, J. (2004). El papel de las analogías en la creatividad de los científicos: La teoría del campo electromagnético de Maxwell como caso paradigmático de la historia de las ciencias. Revista Eureka sobre Enseñanza y Divulgación de las Ciencias, 1(3), 188-205.

Bachelard, G. (2000). La formación del espíritu científico. México: Siglo XXI.

Cantoral, R. (2013). Teoría Socioepistemológica de la Matemática Educativa. España: Gedisa.

Cantoral, R. y Farfán, R. (2003). Matemática Educativa: una visión de su evolución. Revista Latinoamericana de Investigación en Matemática Educativa, 6(1), 27-40.

Cantoral, R., Farfán, R., Lezama, J. y MartínezSierra, G. (2006). Socioepistemología y representación: algunos ejemplos. Revista Latinoamericana de Investigación en Matemática Educativa, (Especial), 83-112.

Cantoral, R., Montiel, G. y Reyes-Gasperini, D. (2015). Análisis del discurso Matemático Escolar en los libros de texto, una mirada desde la Teoría Socioepistemológica. Avances de Investigación en Educación Matemática, 8, 9-28. 
Farfán, R. (2012). Socioepistemología y Ciencia. El caso del estado estacionario y su matematización. España: Gedisa.

Herrera, R. (1990). Crítica al modelo ortodoxo de la enseñanza de la ingeniería e ideas para su modificación. Tecnología en marcha, 10(1), 3-16.

Hinojos, J. y Farfán, R. (2017a). Breve recorrido por el discurso matemático escolar de la serie de Fourier en el contexto del ingeniero en electrónica. Acta Latinoamericana de Matemática Educativa, 30, 838846.

Hinojos, J. y Farfán, R. (2017b). Acerca de las nociones de estabilidad en electricidad, la relación entre el calor y la electricidad. Revista de História da Educação Matemática, 3(3), 68-100.

Lerman, S. (2000). The Social Turn in Mathematics Education Research. En J. Boaler (Ed.), Multiple Perspectives on Mathematics Teaching and Learning, 19-44. Estados Unidos: Ablex Publishing. Maxwell, J. (1881). A Treatise on Electricity and Magnetism. Reino Unido: Cambridge University Press.

Narasimhan, T. (1999). Fourier's heat conduction equation: History, influence, and connections. Reviews of Geophysics, 37(1), 151-172.

Ohm, G. (1827). Die Galvanische Kette Mathematisch Bearbeitet. Alemania.

Thomson, W. (1872). Reprints of Papers on Electrostatics and Magnetism. Reino Unido: Macmillan \& Co. 